\title{
Evaluation of the lower motor neuron integrity of upper extremity muscles in high level spinal cord injury
}

\author{
M-J Mulcahey*,1, BT Smith ${ }^{1}$ and RR Betz ${ }^{1}$ \\ Shriners Hospitals for Children, Philadelphia, Pennsylvania, USA
}

\begin{abstract}
Purpose: To evaluate the lower motor neuron (LMN) integrity of upper extremity muscles of persons with high tetraplegia $(\mathrm{C} 1-\mathrm{C} 4)$ in order to determine muscles available for stimulation. Methods: Fourteen subjects (23 arms) were evaluated for LMN integrity. Muscles that elicited a functional response (grade 3 or better) to surface electrical stimulation were considered to have intact LMN and good candidates for FES. Strength-duration (S-D) curves were generated on muscles that showed weak (less than grade 3 ) or no response to surface stimulation. Muscles were considered denervated if S-D curves were discontinuous or depicted steep, increasing amplitude for pulse durations greater than $1 \mathrm{~m}$.

Results: Muscles for grasp and release had intact LMN in 19 of $23(83 \%)$ arms. The wrist extensors and flexors and pronator were excitable in 17 (74\%), $20(87 \%)$ and $19(83 \%)$ arms, respectively. The supinator demonstrated LMN lesion in $80 \%$ of the arms. Over $90 \%$ of the biceps muscles were unresponsive to electrical stimulation and $85 \%$ and $87 \%$ of the deltoid and supraspinatus muscles, respectively, were not electrically excitable. The latissimus dorsi and triceps muscles were typically innervated $(78 \%$ and $91 \%$, respectively) and slightly more than half $(52 \%)$ of the pectoralis major muscles were excitable.

Conclusion: These data suggest that application of FES in high tetraplegia for hand and arm function would require augmentation because of the inability to stimulate the elbow flexors, deltoid and rotator cuff muscles. These data also show that several paralyzed proximal muscles with intact LMN that have been historically transferred to address shoulder paralysis in other patient populations are available for transfer and stimulation in the population with high level spinal injuries.
\end{abstract}

Keywords: tetraplegia; functional electrical stimulation; tendon transfers; upper extremity reconstruction

\section{Introduction}

Over the past three decades, considerable technological development has greatly improved the ability of functional electrical stimulation (FES) to restore movement following spinal cord injury (SCI), including upper ${ }^{1-3}$ and lower $^{3-5}$ extremity movement, bladder and bowel function ${ }^{6,7}$ and respiratory capacity. ${ }^{8,9}$

Successful application of any FES system requires that the lower motor neuron (LMN) and muscle fibers it supplies are intact and capable of responding to stimulus pulses of short duration. ${ }^{10}$ Although denervated muscle is capable of responding directly to stimulus pulses of long duration, the forcefulness of the contraction is usually insufficient for functional applications because only the muscle fibers in the vicinity of the stimulating electrode will respond. Through sufficient excitation of an intact LMN,

*Correspondence: MJ Mulcahey, MS, OTR, Shriners Hospitals for Children, Philadelphia, 3551 North Broad Street, Philadelphia, PA 19140, USA repeatable and forceful contraction of all portions of the muscle supplied by the nerve can be obtained.

With the exception of injuries to the cauda equina, the concomitant LMN damage that commonly occurs within two levels caudal to the level of SCI often goes unrecognized and has been a focus of few studies. ${ }^{11-15}$ Campbell and colleagues ${ }^{16,17}$ described denervation patterns in 24 persons with SCI between C5 and L3; $45 \%$ of those with thoracolumbar (T12-L3) lesions and over $7 \%$ of those with thoracic (T1-T11) lesions demonstrated LMN impairment. The number in each subgroup was not reported. In a study conducted by Peckham, et al, ${ }^{18}$ peripheral innervation to the muscles required for stimulated prehension and release was intact in the majority of 24 clients with SCI between $\mathrm{C} 4$ and $\mathrm{C} 7$. In a prior study from our institution ${ }^{19}$, $40 \%$ of 113 children and adolescents with SCI demonstrated LMN impairment; slightly more than $20 \%$ of 61 children with mid-cervical (C5-C7) tetraplegia had LMN impairment to key muscles for stimulated hand function and $70 \%$ of children with 
paraplegia had LMN lesions that inhibited their use of FES for standing and walking.

The literature describing the occurrence of LMN lesions in persons with high tetraplegia $(\mathrm{C} 1-\mathrm{C} 4)$ is even more limited. Doerr and Long ${ }^{20}$ found LMN lesions in the biceps muscle in three of four persons with $\mathrm{C} 4$ SCI. Peckham ${ }^{18}$ identified LMN lesions in one of three subjects with $\mathrm{C} 4 \mathrm{SCI}$; he suggested that similar LMN lesions of proximal shoulder muscles should also be anticipated, and may greatly reduce the benefits of FES for persons with $\mathrm{C} 4$ level SCI unless an additional power source can be provided. Reports by Hoshimiya and Nathan support Peckham concerning the need for alternative power sources. Hoshimiya ${ }^{21}$ required a balance forearm orthosis (BFO) to provide proximal stability when he employed intramuscular stimulation controlled by sip and puff sensors for hand grasp and release and elbow extension and flexion. Nathan $^{22}$ utilized an overhead sling for shoulder support when he applied surface stimulation activated by voice control for hand and arm function. In both studies, FES, combined with orthotic support at the shoulder, enabled several clients with high tetraplegia to perform simple table top activities such as writing, drinking and eating. Our pilot work on FES and high tetraplegia ${ }^{23,24}$ also confirmed the presence of LMN lesions in muscles innervated at $\mathrm{C} 5$ and reaffirmed the need for alternative power sources at the elbow and shoulder. We performed a bipolar muscle transfer of the paralyzed but electrically excitable latissimus dorsi to overcome the inability to stimulate the elbow flexors. In conjunction with an overhead sling, stimulated elbow flexion and FES for grasp and release enabled an adolescent with a $\mathrm{C} 4$ level SCI and C5 LMN impairment the ability to perform handto-mouth activities after set-up. The limitation of the FES system for this adolescent included lack of voluntary or stimulated shoulder external rotation and the cosmesis, awkwardness, poor reliability and set-up difficulty associated with the overhead sling.

The frequency of LMN lesions in the population with SCI justifies careful evaluation especially when applications of FES are being considered. While the nature of LMN lesions of muscles of the hand in persons with mid-cervical tetraplegia (C5-C7) has been formally explored, little has been done to determine the tendency of LMN lesions of proximal muscles of persons with high level spinal injuries (C1-C4). The purpose of this study was to evaluate the nature and tendency of LMN lesions in select upper extremity muscles in young people with high tetraplegia, to determine muscles available for stimulation. The significance of the study is derived from gains realized by persons with mid-cervical SCI who have been outfitted with the Freehand System ${ }^{\circledR}$ (NeuroControl Corporation, Cleveland, Ohio, USA) an 8-channel totally implantable FES system designed to restore hand function to persons with $\mathrm{C} 5 \mathrm{SCI}^{1,2}$, and its potential to provide upper extremity function to persons who have sustained high level spinal injuries.

\section{Methods}

\section{Subjects}

Fourteen subjects (23 arms) with high level tetraplegia (C1-C4) were evaluated. As shown in Table 1, each subject sustained a traumatic onset spinal injury and, at the time of evaluation, were at least 1 year post injury. So as not to skew the data, subjects were excluded from this study if the nature of their injury was viral (ie: transverse myelitis), vascular or iatrogenic (ie: tumor removal; cardiac surgery); these types of pediatric SCI almost always result in some degree of LMN lesion. One subject (two arms) had a C2 level SCI and two subjects (four arms) had C3 level injuries; the remaining 11 subjects ( $17 \mathrm{arms})$ had injuries at the C4 level.

\section{Test procedure}

Muscle responses to surface electrical stimulation were evaluated using the UltraStim ${ }^{\mathrm{TM}}$ (Neuromedics, Inc., Clute, TX, USA). For each muscle, a biphasic waveform was applied with a pulse duration between $0-200$ us, frequency of 12 or 16 hertz and a current adjusted to elicit a muscle contraction. Each muscle that elicited at least a grade 3 stimulated response to surface stimulation was considered to have intact lower motor neuron. For each muscle that elicited a weak (less than grade 3 ) or no response, a strength-duration (S-D) curve 25,26 was generated using amplitudes that elicited a visible twitch response to pulse durations of $100,50,10,3,2,1,0.8,0.6,0.4,0.3$ and $0.1 \mathrm{~m}, \mathrm{~S}-\mathrm{D}$ curves were generated using the Dynatron 438 (EnrafNonius, West Germany). Muscles were considered denervated if S-D curves were discontinuous or depicted a steep, increasing amplitude for pulse durations greater than $1 \mathrm{~m}$. The shape of the S-D

Table 1 Subject profiles

\begin{tabular}{lclcc}
\hline Subject & $\begin{array}{c}\text { Age in } \\
\text { years }\end{array}$ & $\begin{array}{l}\text { Cause of } \\
\text { injury }\end{array}$ & \multicolumn{2}{c}{$\begin{array}{c}\text { Asia classification } \\
\text { Lue }\end{array}$} \\
\hline 1 & 5 & MVA & C2 & C2 \\
2 & 17 & football & C3 & C3 \\
3 & 8 & MVA & C3(incomplete) C3(incomplete) \\
4 & 11 & gymnastics & C4 & C4 \\
5 & 16 & diving & C4 & C4 \\
6 & 12 & MVA & C4 & C4 \\
7 & 17 & diving & C4 & C4 \\
8 & 18 & MVA- & & \\
& & pedestrian & C4 & C4 \\
9 & 16 & MVA & C4 & C4 \\
10 & 14 & MVA & C5* & C4 \\
11 & 16 & fall & C5* & C4 \\
12 & 17 & MVA & C5* & C4 \\
13 & 11 & diving & C5* & C4 \\
14 & 16 & MVA & C4 & C5* \\
\hline
\end{tabular}

Sample consists of 14 subjects $(23$ arms $)$ with high tetraplegia. *Denotes motor level of mid-cervical level SCI and was excluded from analyses 
curve is considered diagnostic of LMN integrity because a point is reached at which denervated muscle is not capable of responding with a twitch while an innervated muscle can. ${ }^{25,26,27}$ As shown in Figure 1, in a normally innervated muscle, no increase in the stimulus amplitude beyond rheobase (the amplitude at which a threshold motor response is obtained when an essentially infinite pulse duration is applied) is needed to elicit a threshold response for pulse durations from $1-100 \mathrm{~m}$. In contrast, a denervated muscle (Figure 1) will require increased amplitude to elicit a threshold response for pulse durations shorter than the rheobase duration and will not respond to durations shorter than $1 \mathrm{~m}$. Discontinuous curves, indicative of partial denervation (Figure 1), reflect elements of both an innervated and denervated muscle S-D profile. $25,26,27$

The authors chose to employ the S-D test (rather than electromyography (EMG) for several reasons. First, S-D testing has been shown to be a reliable means to determine LMN integrity in children with SCI. $^{28}$ Strength-duration testing is non-invasive and can be conducted by trained and licensed physical or occupational therapists as part of the comprehensive physiological evaluation. In addition, a thorough EMG analysis requires volitionally controlled lowlevel and maximum contractions by the patient. The subjects in this study lacked voluntary control over the muscles under investigation.

Eleven muscles were tested in the proximal arm or shoulder including the biceps, brachioradialis, brachialis, middle deltoid, supraspinatus, triceps, pectoralis major and latissimus dorsi. In addition, key hand and forearm muscles for grasp and release, forearm rotation and wrist motion were also tested.

One therapist (primary author) experienced in FES and electrodiagnostic testing using surface electrical stimulation performed all of the evaluations. For several muscles that demonstrated inconsistent responses to stimulation or yielded results indicative of partial denervation, interpretation of $\mathrm{S}-\mathrm{D}$ curves were confirmed by a physical therapist who is a neurology certified specialist.

\section{Results}

Tables 2 and 3 show, for each subject, the innervation status of the tested distal and proximal muscles, respectively. The muscles for grasp and release (finger and thumb flexors and extensors and thumb adductor and abductor) were stimulatable in 19 of $23(83 \%)$ arms. In three hands $(13 \%)$, all of the muscles for grasp and release had LMN lesion involvement; one hand tested partially denervated in the finger and thumb extensors. Similarly, the wrist extensors and flexors and pronator teres were stimulatable in 17 $(74 \%), 20(87 \%)$, and $19(83 \%)$ arms, respectively. The supinator demonstrated LMN lesion in all but five arms $(79 \%)$. As shown in Table 3, over $90 \%$ of the biceps muscles were unresponsive to electrical stimula- tion and $85 \%$ and $87 \%$ of the deltoid and supraspinatus muscles, respectively, were not electrically excitable. The implications of these LMN lesions to the application of FES for persons with high tetraplegia are described in Table 4.

\section{Discussion}

The results of this study support earlier findings $18,20,21,22$ suggesting a relatively high tendency for LMN lesions of proximal arm muscles following high tetraplegia, especially $\mathrm{C} 3$ and $\mathrm{C} 4$ level SCI. In this series of 24 arms, LMN lesions of the elbow flexors and proximal shoulder muscles were present in $91 \%$ and more than $80 \%$ of the cases, respectively. For the subjects with $\mathrm{C} 3$ and $\mathrm{C} 4 \mathrm{SCI}$, the inability to stimulate these muscles was anticipated since the muscles are supplied by C5, just caudal to the SCI. Conversely, LMN lesions caudal to C5 were few; only one subject (\#5) would be excluded from FES for grasp and release due to the inability to excite distal forearm and hand muscles. Unfortunately, however, little is gained if stimulated hand function is restored in the absence of elbow flexion and proximal stability.

Balanced forearm orthoses $(\mathrm{BFO})^{29}$ or overhead slings $^{23}$ are unable to provide the level of proximal stability or arm control necessary to facilitate successful use of a clinical FES hand system by persons with motor complete high tetraplegia. ${ }^{21,23}$ Both types of orthoses are designed to support the weight of the limb so that weak shoulder muscles (typically innervated at C5) can move the arm through a purposeful range, ${ }^{31}$ in the absence of voluntary or FES-excitable muscles both the BFO and overhead sling may simply provide a support to protect the glenohumeral joint. Nevertheless, in our experience, few persons would accept these orthoses on a day-to-day basis because of difficulty in set-up and cosmesis.

\section{Strength-Duration Diagram}

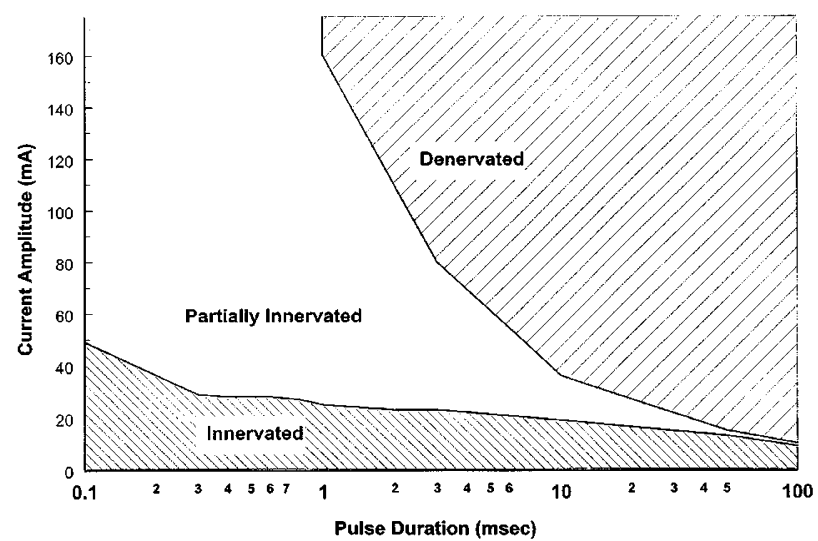

Figure 1 Diagram depicting approximate regions on the S-D plot which define the LMN innervation status 
Table 2 Innervation status of distal upper extremity muscles

\begin{tabular}{|c|c|c|c|c|c|c|c|c|c|c|c|c|c|c|c|c|c|c|c|c|c|c|c|c|c|c|c|c|c|}
\hline \multirow[t]{2}{*}{ Subject } & \multirow[t]{2}{*}{ Level } & \multicolumn{2}{|c|}{$\begin{array}{l}\text { Supinator } \\
\text { C5-6 }\end{array}$} & \multicolumn{2}{|c|}{$\begin{array}{l}\text { Pronator } \\
\text { C6-7 }\end{array}$} & \multicolumn{2}{|c|}{$\begin{array}{l}\text { ECRL } \\
\text { C6-8 }\end{array}$} & \multicolumn{2}{|c|}{$\begin{array}{l}\text { ECRB } \\
\text { C6-8 }\end{array}$} & \multicolumn{2}{|c|}{$\begin{array}{l}\text { ECU } \\
\text { C6-8 }\end{array}$} & \multicolumn{2}{|c|}{$\begin{array}{l}\text { FCU } \\
\text { C7-T1 }\end{array}$} & \multicolumn{2}{|c|}{\begin{tabular}{|l|} 
FCR \\
C6-8
\end{tabular}} & \multicolumn{2}{|c|}{$\begin{array}{l}E D C \\
C 6-8\end{array}$} & \multicolumn{2}{|c|}{$\begin{array}{l}\text { EPL } \\
\text { C6-8 }\end{array}$} & \multicolumn{2}{|c|}{$\begin{array}{l}\text { FDS } \\
\text { C7-T1 }\end{array}$} & \multicolumn{2}{|c|}{$\begin{array}{l}\text { FDP } \\
\text { C7-T1 }\end{array}$} & \multicolumn{2}{|c|}{$\begin{array}{l}\text { FPL } \\
\text { C6-T1 }\end{array}$} & \multicolumn{2}{|c|}{$\begin{array}{l}\text { AdP } \\
\text { C8-T1 }\end{array}$} & \multicolumn{2}{|c|}{\begin{tabular}{|l|} 
AbPB \\
C6-T1
\end{tabular}} \\
\hline & & L & $R$ & L & $\mathrm{R}$ & $L$ & $R$ & L & $R$ & $\mathrm{~L}$ & $\mathrm{R}$ & L & $R$ & $\mathrm{~L}$ & $R$ & $\mathrm{~L}$ & $\mathrm{R}$ & L & $\mathrm{R}$ & L & $\mathrm{R}$ & L & $\mathrm{R}$ & L & $\mathrm{R}$ & L & $\mathrm{R}$ & L & $R$ \\
\hline 1 & C2 & 1 & 1 & 1 & I & 1 & 1 & 1 & 1 & 1 & 1 & I & I & 1 & 1 & 1 & 1 & 1 & 1 & 1 & 1 & 1 & 1 & 1 & 1 & 1 & 1 & 1 & 1 \\
\hline 2 & $\mathrm{C} 3$ & & & 1 & 1 & 1 & 1 & 1 & I & 1 & I & 1 & 1 & 1 & 1 & 1 & 1 & 1 & 1 & 1 & 1 & 1 & 1 & 1 & 1 & 1 & 1 & 1 & 1 \\
\hline 3 & $\mathrm{C} 3$ & & & 1 & I & 1 & 1 & 1 & 1 & 1 & 1 & 1 & 1 & 1 & 1 & 1 & 1 & 1 & 1 & 1 & 1 & 1 & 1 & 1 & I & 1 & 1 & I & 1 \\
\hline 4 & $\mathrm{C} 4$ & & & & I & 1 & I & 1 & 1 & 1 & 1 & 1 & 1 & 1 & 1 & 1 & 1 & 1 & 1 & 1 & 1 & 1 & 1 & 1 & I & 1 & 1 & 1 & 1 \\
\hline 5 & $\mathrm{C} 4$ & & & & & & & & & & & & & & & & & & & & & & & & & & 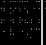 & & \\
\hline 6 & $\mathrm{C} 4$ & & & 1 & 1 & 1 & & 1 & & 1 & 1 & 1 & 1 & 1 & I & 1 & & 1 & & 1 & 1 & 1 & 1 & 1 & 1 & 1 & 1 & 1 & 1 \\
\hline 7 & $\mathrm{C} 4$ & & & 1 & 1 & 1 & 1 & 1 & 1 & 1 & 1 & 1 & 1 & 1 & 1 & 1 & 1 & 1 & 1 & 1 & 1 & 1 & 1 & 1 & 1 & 1 & 1 & 1 & I \\
\hline 8 & C4 & & & 1 & 1 & 1 & I & 1 & 1 & 1 & 1 & 1 & 1 & 1 & 1 & I & 1 & 1 & 1 & 1 & 1 & 1 & I & 1 & 1 & 1 & 1 & 1 & I \\
\hline 9 & $\mathrm{C} 4$ & the & 1 & \%. & 1 & 2. & 1 & e & 1 & ? & 1 & . & 1 & . & 1 & . & 1 & . & 1 & re. & 1 & . & 1 & 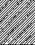 & 1 & 6 & 1 & ? & 1 \\
\hline 10 & $C 4 / 5$ & * & & * & 1 & * & 1 & * & 1 & * & 1 & * & I & $*$ & 1 & * & 1 & * & 1 & * & 1 & * & 1 & * & 1 & * & 1 & * & I \\
\hline 11 & $\mathrm{C} 4 / 5$ & * & 3 & * & 1 & * & 1 & * & 1 & * & 1 & * & 1 & $*$ & 1 & * & 1 & * & 1 & * & 1 & * & 1 & * & 1 & * & I. & * & 1 \\
\hline 12 & $\mathrm{C} 4 / 5$ & * & 1 & * & 1 & * & 1 & * & 1 & * & 1 & * & 1 & * & 1 & * & 1 & * & 1 & * & 1 & * & 1 & * & 1 & * & 1 & * & 1 \\
\hline 13 & $\mathrm{C} 4 / 5$ & * & & * & 1 & * & We & * & t. & * & 1 & * & 1 & $*$ & 1 & * & I & * & 1 & * & 1 & * & I & * & 1 & * & 1 & * & 1 \\
\hline 14 & $\mathrm{C} 4 / 5$ & * & 1 & * & 1 & & * & & * & 1 & * & 1 & * & 1 & * & 1 & * & 1 & * & 1 & * & 1 & * & 1 & * & 1 & * & 1 & * \\
\hline
\end{tabular}

I - innervated; Lightly shaded - Partial Denervation; Heavily shaded - Denervated; NT - not tested; *C5 Motor Level (excluded from study)

Table 3 Innervation status of proximal upper extremity muscles

\begin{tabular}{|c|c|c|c|c|c|c|c|c|c|c|c|c|c|c|c|c|c|c|c|c|c|}
\hline \multirow[t]{2}{*}{ Subject } & \multirow[t]{2}{*}{ Level } & \multicolumn{2}{|c|}{$\begin{array}{l}\text { Supra- } \\
\text { spinatus } \\
\text { (C4-6) }\end{array}$} & \multicolumn{2}{|c|}{$\begin{array}{l}\text { Biceps } \\
\text { (C5-6) }\end{array}$} & \multicolumn{2}{|c|}{$\begin{array}{l}\text { Brachio- } \\
\text { radialis } \\
\text { (C5-6) }\end{array}$} & \multicolumn{2}{|c|}{$\begin{array}{l}\text { Brachialis } \\
\text { (C5-6) }\end{array}$} & \multicolumn{2}{|c|}{$\begin{array}{l}\text { Middle } \\
\text { Deltoid } \\
\text { (C5-6) }\end{array}$} & \multicolumn{2}{|c|}{$\begin{array}{l}\text { Serratus } \\
\text { Anterior } \\
\text { (C5-7) }\end{array}$} & \multicolumn{2}{|c|}{$\begin{array}{l}\text { Teres } \\
\text { Minor } \\
\text { (C5-7) }\end{array}$} & \multicolumn{2}{|c|}{$\begin{array}{l}\text { Latissimus } \\
\text { Dorsi } \\
\text { (C5-8) }\end{array}$} & \multicolumn{2}{|c|}{$\begin{array}{l}\text { Triceps } \\
\text { (C6-8) }\end{array}$} & \multicolumn{2}{|c|}{$\begin{array}{l}\text { Pectoralis } \\
\text { Major } \\
\text { (C5-8,T1) }\end{array}$} \\
\hline & & $L$ & $R$ & L & $R$ & $L$ & $\mathrm{R}$ & L & $R$ & $\mathrm{~L}$ & $R$ & L & $\mathrm{R}$ & L & $R$ & $L$ & $\mathrm{R}$ & L & $\mathrm{R}$ & L & $\mathrm{R}$ \\
\hline 1 & $\mathrm{C} 2$ & I & 1 & 1 & 1 & 1 & 1 & 1 & 1 & 1 & 1 & 1 & I & 1 & 1 & 1 & I & 1 & 1 & 1 & 1 \\
\hline 2 & $\mathrm{C} 3$ & & & & & & & & & & & NT & NT & . & & r. & re & 1 & 1 & & \\
\hline 3 & $\mathrm{C} 3$ & & & & & & & ? & & & & NT & NT & I & U. & 1 & 1 & 1 & 1 & 1 & 1 \\
\hline 4 & C4 & & & & & & & & & & & NT & NT & 6. & NT & 1 & 1 & 1 & 1 & 1 & 1 \\
\hline 5 & C4 & & & & & & & & & & & & . & & & & & & & & \\
\hline 6 & $\mathrm{C} 4$ & & & & & & & & & & & NT & NT & . & & 1 & 1 & 1 & 1 & (2) & I \\
\hline 7 & $\mathrm{C} 4$ & & & & & & & & & & & 1 & 1 & 1 & 1 & 1 & 1 & 1 & 1 & 1 & 1 \\
\hline 8 & $\mathrm{C} 4$ & & & & & & & & & & & & 1 & 1 & 1 & 1 & 1 & 1 & 1 & 1 & 1 \\
\hline 9 & C4 & & I & & & & & & & & & (2). & 1 & fi. & 1 & res. & 1 & 1 & 1 & & \\
\hline 10 & $C 4 / 5$ & * & & * & & * & & * & & $*$ & C. & * & 1 & * & 1 & * & 1 & * & 1 & * & e \\
\hline 11 & $\mathrm{C} 4 / 5$ & * & & * & & * & & * & & $\star$ & & * & NT & * & - & * & 1 & * & 1 & * & 1 \\
\hline 12 & $\mathrm{C} 4 / 5$ & * & & * & & * & & * & & * & 1 & . & 1 & * & 1 & $*$ & 1 & ${ }^{*}$ & 1 & $*$ & \\
\hline 13 & $\mathrm{C} 4 / 5$ & * & 10 & * & & * & & * & & * & 1 & . & 1 & * & 1 & * & 1 & * & 1 & * & \\
\hline 14 & $\mathrm{C} 4 / 5$ & 8 & * & & * & & * & c. & * & . & * & NT & * & 1 & * & 1 & * & 1 & * & . & * \\
\hline
\end{tabular}

I - Innervated; Lightly shaded - Partial denervation; Heavily shaded - Denervated; NT - not evaluated; *C5 Motor level (excluded from study) 
However, principles of traditional soft tissue reconstruction may provide successful techniques to overcome the barriers associated with stimulating muscles with LMN lesions. For example, we $\mathrm{e}^{2,30}$ and others $^{32}$ have successfully transferred and stimulated paralyzed but electrically excitable muscles to overcome the problems related to stimulating hand muscles with LMN lesions in persons with mid-cervical level SCI. One adolescent FES user underwent transfer and stimulation of the paralyzed flexor carpi ulnaris to augment stimulated finger flexion. ${ }^{33}$ Users of the Freehand System $^{\mathbb{R}}$, (NeuroControl Corporation, Cleveland, Ohio, USA) routinely undergo tendon transfers and stimulation of paralyzed muscles to take the place of the paralyzed and denervated radial wrist extensors ${ }^{32}$ and other key muscles for grasp and release. $^{2}$ Transfer of paralyzed muscles for the purpose of FES has been largely influenced by the techniques and principles of tendon transfers for voluntary hand function. ${ }^{34-36}$

Tendon transfers have also been performed to restore voluntary elbow flexion and shoulder external rotation in persons with a variety of diagnoses including arthrogryposis, poliomyelitis, brachial plexus injuries and traumatic nerve injuries. ${ }^{37-44}$ Surgical restoration of voluntary elbow flexion has been successfully obtained following transfer of the triceps muscle, ${ }^{37}$ pectoralis major and/or minor muscles $^{38-41}$ and the latissimus dorsi muscle. ${ }^{42-44}$ Voluntary external rotation has also been achieved via transfer of the latissimus dorsi muscle. As outlined in Table 4, this study showed that although UMN lesions were present, LMN integrity was intact in the majority of the latissimus dorsi (78\%) and triceps $(91 \%)$ muscles rendering them available for transfer and stimulation. Slightly more than $50 \%$ of the

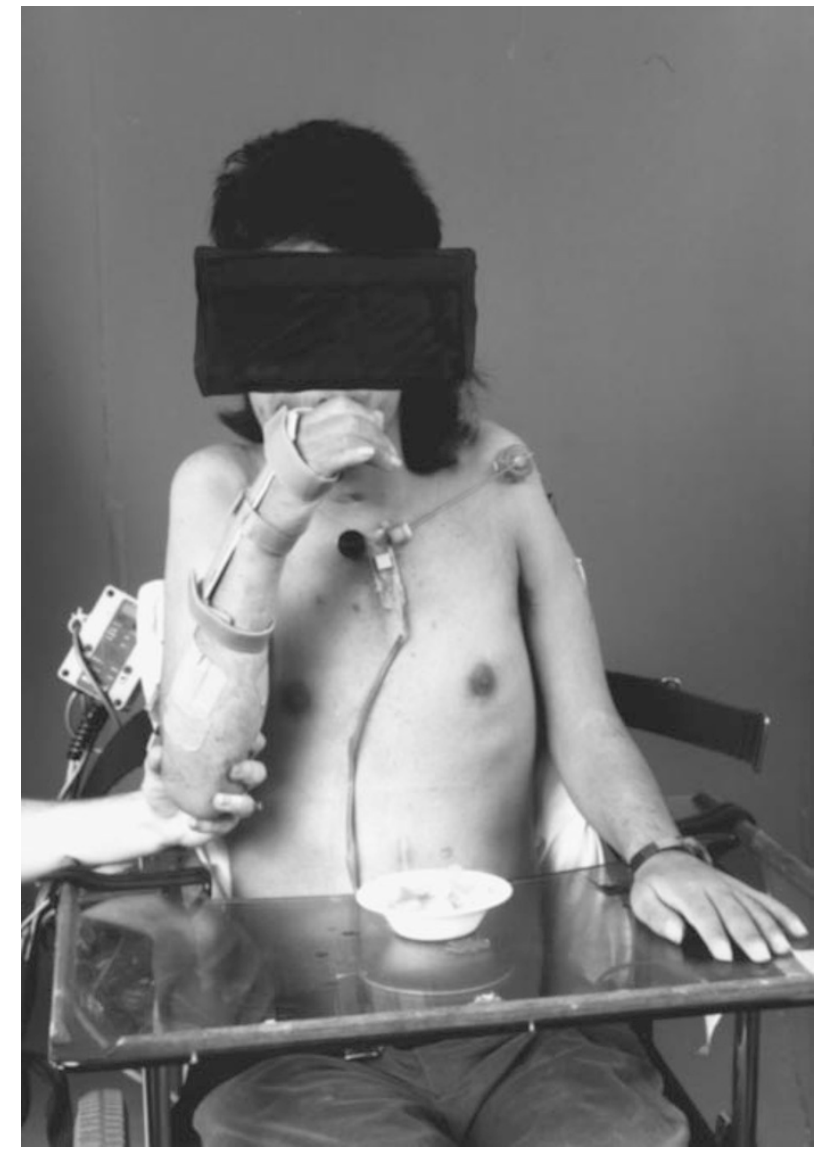

Figure 2 An adolescent with C4 level SCI and LMN lesion of the biceps. The latissimus dorsi muscle was transferred and stimulated for elbow flexion. Note the support provided at the posterior aspect of the arm to prevent the shoulder from internal rotation

Table 4 Number of stimulatable back, shoulder and elbow muscles among the 23 arms studied

\begin{tabular}{|c|c|c|c|}
\hline Muscle & $\begin{array}{l}\text { Innervated } \\
\text { (Electrically } \\
\text { Excitable) }\end{array}$ & $\begin{array}{c}\text { LMN Lesion } \\
\text { (Not Electrically } \\
\text { Excitable) }\end{array}$ & Implications to application of FES \\
\hline Latissimus Dorsi & $18(78 \%)$ & $5(22 \%)$ & $\begin{array}{l}\text { Stimulatable; can be transferred and stimulated for elbow flexion } \\
\text { external rotation }\end{array}$ \\
\hline Supraspinatus & $3(13 \%)$ & $20(87 \%)$ & $\begin{array}{l}\text { Not stimulatable; therefore require soft tissue procedure or orthoses for } \\
\text { shoulder stability }\end{array}$ \\
\hline Pectoralis Major & $12(52 \%)$ & $11(48 \%)$ & $\begin{array}{l}\text { Stimulatable; can be transferred and stimulated for elbow flexion or } \\
\text { shoulder forward flexion or stimulated in original position for shoulder } \\
\text { adduction }\end{array}$ \\
\hline Middle Deltoid & $4(17 \%)$ & $19(83 \%)$ & $\begin{array}{l}\text { Not stimulatable; therefore require soft tissue procedure or orthoses for } \\
\text { shoulder stability }\end{array}$ \\
\hline Biceps & & & \\
\hline $\begin{array}{l}\text { Brachioradalis } \\
\text { Brachialis }\end{array}$ & $2(2 \%)$ & $21(91 \%)$ & Not stimulatable; therefore require muscle transfer for elbow flexion \\
\hline Triceps & $21(91 \%)$ & $2(2 \%)$ & $\begin{array}{l}\text { Stimulatable; can be transferred and stimulated for elbow flexion or } \\
\text { stimulated in original position for elbow extension }\end{array}$ \\
\hline
\end{tabular}

As expected, the elbow flexors, middle deltoid and supraspinatus were generally denervated (not simulatable) but the triceps, pectoralis major and latissimus dorsi were inervated (stimulatable). The ability to stimulate the later three muscles is encouraging since for each of them, the muscle can be transferred so that when it is stimulated it can provide elbow flexion or shoulder function 
pectoralis major muscles were also electrically excitable and available for tendon transfer.

In our pilot work, we successfully transferred and stimulated the paralyzed but excitable latissimus dorsi to take the place of the paralyzed and unresponsive elbow flexors. With stimulation to the latissimus dorsi, elbow flexion was obtained (Figure 2), enabling an adolescent with $\mathrm{C} 4$ tetraplegia to utilize a FES hand system to feed himself. ${ }^{23}$ Lack of voluntary external rotation and the inability to stimulate the infraspinatus because of LMN lesion limited the clinical usefulness of FES for this client. Results of the current study provide information on several paralyzed muscles with intact LMN that could be transferred for stimulated shoulder external rotation. For example, the latissimus dorsi could be transferred to the external rotators for stimulated shoulder external rotation and the triceps or pectoralis major transferred for stimulated elbow flexion.

\section{Conclusion}

Lower motor neuron lesions of key muscles for stimulated shoulder and arm function may be prevalent in persons with high tetraplegia and therefore, may greatly reduce the potential benefits of FES for this population. However, there was a tendency for some muscles which historically have been transferred to restore voluntary elbow and shoulder motion in other patient populations, to be excitable by electrical stimulation. Transfer and stimulation of paralyzed muscles with intact LMN should be further studied as a means to address LMN lesions of key muscles needed for successful application of upper extremity FES systems in persons with high level tetraplegia.

\section{Acknowledgements}

This study was supported by Shriners Hospitals for Children Grant \# 8530. Grateful appreciation to Elizabeth Gardner MS, PT, NCS who assisted with the implementation and interpretation of the electrodiagnostic testing.

\section{References}

1 Kilgore KL et al. An implanted upper-extremity neuroprosthesis. J Bone Joint Surg 1997; 79A: 533-541.

2 Mulcahey MJ et al. Implanted functional electrical stimulation hand system in adolescents with spinal injuries: an evaluation. Arch Phys Med Rehab 1997; 78: 597-607.

3 Marsolais EB et al. Augmentation of transfers for a quadriplegic patient using an implanted FNS system: Case report. Paraplegia 1994; 32: $573-579$.

4 Kantor C et al. Report on a conference on motor prostheses for workplace mobility of paraplegic patients in North America. Paraplegia 1993; 31: 439-456.

5 Mulcahey MJ, Betz RR. Upper and lower extremity applications of functional electrical stimulation: A decade of research with children and adolescents with spinal injuries. Pediatric Physical Therapy 1997; 9: $113-122$.
6 Creasy GH. Electrical stimulation of sacral roots for micturition after spinal cord injury. Urol Clin North Am 1993; 20: 505-515.

7 Brindley GS et al. Sacral anterior root stimulators for bladder control in paraplegia: The first 50 cases. J Neurol Neurosurg Psychiatry 1986; 49: $1104-1114$.

8 Glenn WW et al. Twenty years of experience in phrenic nerve stimulation to pace the diaphragm. Pacing Clin Electrophysiol 1988; 11: $2135-2141$.

9 Hunt CE et al. Diaphragm pacing in infants and children. Pacing Clin Electrophysiol 1988; 11: 2135-2141.

10 Baker LL. Neuromuscular stimulation in the restoration of purposeful limb movements. In: Wolf SL (ed). Electrotherapy. Churchill Livingstone: New York 1981, pp 25-48.

$11 \mathrm{Wu}$ L, Marino RJ, Herbison GJ, Ditunno JF. Recovery of zerograde muscles in the zone of partial preservation in motor complete quadriplegia. Arch Phys Med Rehabil 1992; 73: 4043.

12 Benzel EC, Larson SJ. Recovery of nerve root function after complete quadriplegia from cervical spine fractures. Neurosurg 1986; 19: $809-812$.

13 Ditunno JF et al. Wrist extensor recovery in traumatic quadriplegia. Arch Phys Med Rehabil 1987; 68: 287-290.

14 Yang JF, Stein RB, Jhamandas J, Gordon T. Motor unit numbers and contractile properties after spinal cord injury. Ann Neurol 1990; 28: 496-502.

15 Little JW et al. Electrodiagnoses of upper limb weakness in acute quadriplegia. Am J Phys Med Rehabil 1994; 73: 15-22.

16 Campbell $\mathbf{J}$ et al. Innervation status of muscles paralyzed by spinal cord injury. Proc $15^{\text {th }}$ Ann ASIA Scientific Meeting. 1989 American Spinal Injury Association, Las Vegas, NV.

17 Campbell J, Meadows P. Therapeutic FES: from rehabilitation to neural prosthesis. Assistive Technology 1992; 4: 4-18.

18 Peckham PH, Mortimer JT, Marsolais EB. Upper and lower motor neuron lesions in the upper extremity muscles of tetraplegics. Paraplegia 1976; 14: 115-121.

19 Triolo RJ, Betz RR, Mulcahey MJ, Gardner ER. Application of functional neuromuscular stimulation to children with spinal cord injuries: candidate selection for upper and lower extremity research. Paraplegia 1994; 32: 824-843.

20 Doerr GM, Long C. Electrical response and electromyograms of upper-extremity muscles in quadriplegics. Orthotics and Prosthetics 1969; 23: 20-26.

21 Hoshimiya N, Naito A, Yajima M, Handa Y. A multichannel FES system for the restoration of motor functions in high spinal cord injury patients: a respiration-controlled system for multijoint upper extremity. IEEE Trans Biomed Eng 1989; 36: $754-$ 760.

22 Nathan RH. An FNS-based system for generating upper limb function in the C4 quadriplegic. Med Biol Eng Comp 1989; 27: $549-556$.

23 Betz RR et al. Bipolar latissimus dorsi transposition and functional neuromuscular stimulation to restore elbow flexion in an individual with $\mathrm{C} 4$ tetraplegia and $\mathrm{C} 5$ denervation. $J \mathrm{Am}$ Para Soc 1992; 15: 220-228.

24 Smith BT, Mulcahey MJ, Betz RR. Development of an upper extremity FES system for individuals with C4 tetraplegia. IEEE Transactions on Rehabilitation Engineering, 1996; 4: 264-270.

25 Wynn Parry CB. Strength-Duration Curves. In: Light, S.(ed). Electrodiagnosis and Electromyography, 2nd edn. Elizabeth Licht: New Haven, CT 1961, pp 241-271.

26 Robinson AJ. Physiology of muscle and nerve. In: Robinson AJ, Snyder-Macker L (eds). Clinical Electrophysiology. Williams \& Wilkins: Baltimore 1989, pp 110-111.

27 Richardson AT, Wynn-Parry CB. The theory and practice of electrodiagnosis. Ann Phys Med 1957; 4: 41-58.

28 Gardner ER, Sweesy TM, Triolo RJ, Betz RR. Agreement of EMG and strength-duration tests in determining a lower motor neuron lesion in children with spinal cord injures. Proceedings from the Combined Sections Meeting of the Amer Phys Therapy Association 1990, pp 31-33.

29 Miner LJ, Nelson VS. Upper limb orthosis. In: Redford JB, Basmanjian JV, Trautman P (eds). Orthotics Clinical Practice and Rehabilitation Technology. Churchill Livingstone: New York, NY 1995, pp 103-105. 
30 Smith BT, Mulcahey MJ, Davis S, Betz R. Tendon transfers to provide brace-free wrist stability in adolescents with the Freehand system. Proceedings VI International Conference of Surgical Rehabilitation of the Upper Limb in Tetraplegia. Cleveland, OH, May 20-23, 1998 p 68.

31 Eisner TJ. Mobile arm support: Installation and use. Brookfield, II, Fred Sammons, 1975.

32 Keith $\mathrm{M}$ et al. Tendon transfers and functional electrical stimulation for restoration of hand function in spinal cord injury. J Hand Surg 1996; 21A: 89-99.

33 Mulcahey MJ et al. Functional neuromuscular stimulation and surgical reconstruction of the hand in long-term tetraplegia. $\mathrm{J} \mathrm{Am}$ Para Soc 1993; 2: 133.

34 Moberg E. Surgical rehabilitation of the upper limb in tetraplegia. Paraplegia 1990; 28: 330 - 334.

35 McDowell CL, Moberg E, House J. The second international conference on surgical rehabilitation of the upper limb in tetraplegia. J Hand Surg 1994 11A: 604-608.

36 Hentz VR et al. Rehabilitation and surgical reconstruction of the upper limb in tetraplegia: An Update. J Hand Surg 1992; 17A: $964-967$.
37 Carroll R, Hill N. Triceps transfer to restore elbow flexion. $J$ Bone Joint Surg 1970; 2: $239-243$.

38 Clark J. Reconstruction of the biceps brachii by pectoral muscle transposition. Br J Surg 1946; 134: 12 - 13 .

39 Brooks D, Seddon H. Pectoral transplantation for paralysis of the flexors of the elbow. J Bone Joint Surg 1959; 1: 36-43.

40 Atkins R, Bell M, Sharrard W. Pectoralis major transfer for paralysis of elbow flexion in children. J Bone Joint Surg 1985; 4: 640-644.

41 Carroll R, Kleinman W. Pectoralis major transplantation to restore elbow flexion to the paralytic limb. J Hand Surg 1979; 6: $501-507$

42 Stern $\mathrm{P}$ et al. Latissimus dorsi musculocutaneous flap for elbow flexion. J Hand Surg 1982 1: 25-29.

43 Moneim M, Omer G. Latissimus dorsi muscle transfer for restoration of elbow flexion after brachial plexus disruption. $J$ Hand Surg 1986; 1: 135-139.

44 Leffert RD, Pess GM. Tendon transfers for brachial plexus injury. Hand Clinics 1988; 2: 273. 